\title{
Highly active antiretroviral treatment does not increase sexual risk behaviour among French HIV infected injecting drug users
}

\author{
A-D Bouhnik, J P Moatti, D Vlahov, H Gallais, P Dellamonica, Y Obadia and the MANIF \\ 2000 Study Group
}

See end of article for authors' affiliations

\section{Correspondence to:} Dr Y Obadia, ORS-PACA 23 rue Stanislas Torrents, 13006 Marseille, France; orspaca@wanadoo.fr

Accepted for publication 1 February 2002
Study objective: This study examined the impact of highly active antiretroviral therapies (HAART) on sexual risk behaviours of HIV infected injecting drug users (IDUs) included in the French MANIF 2000 cohort study.

Design: Longitudinal analysis including baseline and last follow up characteristics using generalised estimating equations (GEE).

Setting: Hospital departments for specialist AIDS care in south eastern France and inner suburbs of Paris.

Patients: All patients antiretrovial treatment naive, who reported being sexually active at enrolment, and who had at least one follow up visit in the cohort between October 1996 and May 1998 ( $n=188)$. Main results: Of the $188 \mathrm{HIV}$ infected IDUs who were antiretroviral treatment naive at enrolment, 34 were prescribed HAART during follow up. Proportion of patients who reported at least one episode of unprotected sexual intercourse in the previous six months only significantly decreased in the HAART treated group (from $47.1 \%$ to $23.5 \%$, $p=0.008$, compared with $43.5 \%$ to $35.7 \%$ in the rest of the sample, $p=0.10$ ). GEE multivariate model confirmed that prescription of HAART was associated with reduced sexual risk.

Conclusions: The concern that HAART might result in clinical improvement leading to resumption of high risk activities that could inadvertently result in HIV transmission was not supported by these data. Reasons for further reductions in HIV risk with taking HAART remain to be clarified.
$\mathrm{H}$ ighly active antiretroviral therapies (HAART) including protease inhibitors (PIs) have been proved to be effective for decreasing HIV viral loads to undetectable levels, for significantly reducing the incidence of HIV related opportunistic infections, and for restoring a decent quality of life for a high number of HIV infected patients. ${ }^{1}$ However, concerns have been raised that these improvements may increase the opportunities for continued or relapse to risk behaviours among HIV infected persons, ${ }^{2}$ and that they may create a new threat for public health through transmission of HIV viral strains that have already acquired genetic resistance characteristics against actual treatments. ${ }^{3}$ Such concerns may even be more pronounced for specific groups, like HIV infected injecting drug users (IDUs), who are often confined to unsupportive social environments and squalid physical living conditions that create additional barriers for HIV secondary prevention..$^{5-9}$

The MANIF 2000 study provided the opportunity to examine the evolution of sexual risk behaviours in a cohort of French patients HIV infected through injecting drug use whether or not they were prescribed HAART after enrolment.

\section{METHODS}

\section{Study population}

MANIF 2000 is a prospective cohort study, which enrols patients HIV infected through injection drug use, aged 18 years or more, with $\mathrm{CD}^{+}$cell counts $\geqslant 300 / \mathrm{mm}^{3}$, no opportunistic infections, and CDC stage A or B at last visit before entry, in 12 hospital departments of south eastern France (Marseilles, Avignon, Nice) and the inner suburbs of Paris. For each patient, data collected at enrolment and at each six months follow up visit included a medical questionnaire completed by the hospital AIDS specialist at the end of consultation, which contains clinical and biological information as well as prescriptions of antiretroviral treatment. In parallel, in depth data about patient's sociological and psychological characteristics as well as their personal experience with HIV infection and care are obtained by means of two questionnaires: a face to face questionnaire administered by a nurse, and a self administered questionnaire that deals with HIV related risk behaviours. This questionnaire includes 21 questions about type of drug use, frequency of injection, needle sharing and borrowing, and access to drug maintenance treatment during the six months before the visit. It also includes 22 questions about sexual behaviour including occurrence of vaginal, anal, and oral intercourse, number of sexual partners, HIV serological status of main partner, as well as condom use with main and occasional partners during the same period.

All patients who were antiretroviral treatment naive, who reported being sexually active at enrolment, and who had at least one follow up visit in the cohort between October 1996 and May 1998, were included in this analysis. Risky sexual behaviour was defined as a dichotomous variable (yes/no) on the basis of patient's reports that he/she has been engaged in unprotected (that is, without a condom) intercourse at least once during the six months before the visit. Evolution of risky sexual behaviour was compared between enrolment and last follow up visit in the cohort in two groups of patients: those for who prescribing physician started HAART during the follow up period and those who were not prescribed HAART.

Abbreviations: HAART, highly active antiretroviral therapies; IDU; injecting drug user; GEE, generalised estimating equations 
Table 1 Characteristics of HIV infected IDUs according to prescription of HAART (enrolment and last follow up visits in the French MANIF 2000 cohort study) $(n=188)$

\begin{tabular}{|c|c|c|c|c|c|c|}
\hline & \multicolumn{3}{|l|}{ At enrolment } & \multicolumn{3}{|c|}{ At last follow up } \\
\hline & \multicolumn{2}{|c|}{$\begin{array}{l}\text { Was prescribed HAART during } \\
\text { follow up }\end{array}$} & \multirow[b]{2}{*}{$\mathrm{p}$} & \multicolumn{2}{|c|}{ HAART treatment } & \multirow[b]{2}{*}{$\mathrm{p}$} \\
\hline & No $(n=154)$ & Yes $(n=34)$ & & No $(n=154)$ & Yes $(n=34)$ & \\
\hline & mean $(S D)$ & mean $(S D)$ & (1) & mean (SD) & mean $(S D)$ & (1) \\
\hline CD4 cell counts $/ \mathrm{mm}^{3}$ & $550(230)$ & $430(180)$ & $<0.001$ & $520(210)$ & $510(270)$ & NS \\
\hline $\log _{10}$ plasma viral load & $3.99(1.0)$ & $4.72(0.9)$ & $<0.001$ & $3.50(0.9)$ & $3.31(1.1)$ & NS \\
\hline Age & $33(4.3)$ & $33(5.1)$ & NS & - & - & - \\
\hline \multirow{2}{*}{$\begin{array}{l}\text { Time of follow up in the medical department before } \\
\text { enrolment (years) }\end{array}$} & $4.4(2.8)$ & $3.6(3.2)$ & NS & - & - & - \\
\hline & $\%$ & $\%$ & (2) & $\%$ & $\%$ & (2) \\
\hline \multicolumn{7}{|l|}{ Place of residence* } \\
\hline Metropolitan areas & 53.2 & 55.9 & & - & - & \\
\hline Medium size towns & 38.3 & 41.2 & NS & - & - & - \\
\hline Small towns and rural areas & 8.4 & 2.9 & & - & - & \\
\hline Male gender & 68.2 & 64.7 & NS & - & - & - \\
\hline Employed & 29.9 & 29.4 & NS & - & - & - \\
\hline Level of education $\geqslant$ high school certificate & 24.0 & 23.5 & NS & - & - & - \\
\hline Homeless & 4.5 & 2.9 & NS & - & - & - \\
\hline \multicolumn{7}{|l|}{ Time after enrollment for last follow up visit in the cohort } \\
\hline 6 months & - & - & & 12.3 & 14.7 & \\
\hline 12 months & - & - & - & 27.3 & 29.4 & NS \\
\hline 18 months & - & - & & 60.4 & 55.9 & \\
\hline Undetectable viral load & 11.7 & 5.9 & NS & 20.8 & 41.2 & $<0.05$ \\
\hline Depressed $\dagger$ & 55.8 & 64.7 & NS & 46.8 & 52.9 & NS \\
\hline Alcohol consumption $\geqslant 5$ glasses/day $\ddagger$ & 17.8 & 15.4 & NS & 13.0 & 2.9 & NS \\
\hline In drug maintenance treatment (DMT) $\ddagger$ & 37.0 & 26.5 & NS & 38.3 & 26.5 & NS \\
\hline Injected drugs $\ddagger$ & 49.4 & 44.1 & NS & 20.8 & 14.7 & NS \\
\hline \multicolumn{6}{|l|}{ Had sexual intercourse with $\ddagger$} & NS \\
\hline No partner & - & - & & 13.6 & 17.6 & \\
\hline Main partner only & 45.5 & 41.2 & NS & 44.2 & 47.1 & NS \\
\hline Main and occasional partners & 9.7 & 11.8 & & 9.7 & 5.9 & \\
\hline Occasional partners only & 44.8 & 47.1 & & 32.5 & 29.4 & \\
\hline $\begin{array}{l}\text { HIV positive main sexual partner } \\
\text { Had at least one episode of } \neq \text { : }\end{array}$ & 20.1 & 14.7 & NS & 22.7 & 17.6 & NS \\
\hline oral sex & 83.1 & 79.4 & NS & 57.8 & 55.9 & NS \\
\hline anal intercourse & 31.2 & 47.1 & NS & 24.0 & 29.4 & NS \\
\hline Had at least one episode of unprotected sex $\ddagger$ & 43.5 & 47.1 & NS & 35.7 & 23.5 & NS \\
\hline
\end{tabular}

\section{Statistical analysis}

The $\chi^{2}$ test, Fisher's exact test, or Mann-Whitney test were used to compare sociodemographic, clinical, and behavioural characteristics of the two groups of patients at enrolment and at last follow up visit. MacNemar $\chi^{2}$ test was used to compare the proportions of patients who declared injecting drug use and unprotected sexual intercourse between enrolment and follow up within the two groups as well as in the whole sample. To analyse factors associated with HIV related sexual risk behaviour, and in particular to analyse if HAART prescription had an impact on this behaviour, we performed a logistic regression with repeated measures including baseline data and follow up data, using the generalised estimating equations method (GEE). ${ }^{10}$ GEE is a statistical method that permits the marginal expectation of an outcome discrete variable to be described as a function of the covariates while accounting for the correlation among the repeated observations for each given subject. The equations used are extensions

those used in quasi-likelihood. The dependent dichotomous variable used a model for binomial distribution with a logit link function. All variables significantly associated to sexual risk behaviour in an univariate GEE model including baseline and follow up data $(\mathrm{p}<0.05)$ were included in the multivariate GEE model. As visits took place at different moments in time, this analysis allowed us to account for the year of the visit.

\section{RESULTS}

Among the 467 patients who provided informed consent to participate in the MANIF 2000 cohort between October 1996 and May 1998, a total of 188 were antiretroviral treatment naive and reported being sexually active at enrolment, and had at least one follow up visit during this period. Among these 188 patients, a total of 34 were ultimately prescribed HAART during follow up. As table 1 shows, these 34 patients had lower CD4+ cell counts and higher plasma viral loads at enrolment than the rest of the sample. Table 1 shows, however, that they did not differ at enrolment for other characteristics including sociodemographic characteristics, active injecting drug use, participation in maintenance treatment for drug misuse, or sexual behaviours. Frequency of HIV related risk behaviours during the six months before enrolment was rather high: $21.3 \%$ of the whole sample reported at least one episode of sharing injection equipment (syringe, cooker or cotton), and $44.1 \%$ at least one episode of unprotected sexual intercourse.

For those who had been prescribed HAART, mean duration of treatment at the last follow up visit in the cohort was 4.0 months $(S D=1.7)$. Not surprisingly, patients treated with HAART were more likely than untreated patients to have undetectable viral loads at follow up (table 1). Self reports of drug injecting behaviours during the prior six months were significantly reduced at last follow up, when compared with baseline data at enrolment, for the entire sample (from $48.4 \%$ 


\begin{tabular}{|c|c|c|}
\hline & \multicolumn{2}{|c|}{$\begin{array}{l}\text { Likelihood of at least one episode of unprotected } \\
\text { sex* }\end{array}$} \\
\hline & $\begin{array}{l}\text { Odds ratio }(95 \% \mathrm{Cl}) \\
\text { Univariate GEE }\end{array}$ & $\begin{array}{l}\text { Odds ratio ( } 95 \% \mathrm{Cl}) \\
\text { Multivariate GEE }\end{array}$ \\
\hline Gender & 0.81 (0.65 to 1.01$)$ & 1.05 (0.78 to 1.41$)$ \\
\hline Male & 1 & 1 \\
\hline Female & $1.99(1.18$ to 3.35$)$ & $1.82(1.01$ to 3.30$)$ \\
\hline \multicolumn{3}{|l|}{ HAART treatment } \\
\hline No & 1 & 1 \\
\hline Yes & $0.39(0.19$ to 0.83$)$ & $0.40(0.17$ to 0.95$)$ \\
\hline \multicolumn{3}{|l|}{ Undetectable viral load } \\
\hline No & 1 & 1 \\
\hline Yes & $1.10(0.64$ to 1.87$)$ & $1.71(0.90$ to 3.23$)$ \\
\hline \multicolumn{3}{|l|}{ Employed } \\
\hline No & 1 & 1 \\
\hline Yes & $0.83(0.48$ to 1.43$)$ & $0.92(0.49$ to 1.74$)$ \\
\hline \multicolumn{3}{|c|}{ In drug maintenance treatment (DMT)* } \\
\hline No & 1 & 1 \\
\hline Yes & $0.96(0.60$ to 1.54$)$ & $0.59(0.33$ to 1.05$)$ \\
\hline \multicolumn{3}{|l|}{ Depressed $\ddagger$} \\
\hline No & 1 & 1 \\
\hline Yes & 1.62 (1.05 to 2.47$)$ & 1.76 (1.04 to 2.99$)$ \\
\hline \multicolumn{3}{|c|}{ Alcohol consumption $\geqslant 5$ glasses/day $*$} \\
\hline No & 1 & 1 \\
\hline Yes & $2.31(1.28$ to 4.16$)$ & $2.42(1.21$ to 4.82$)$ \\
\hline \multicolumn{3}{|l|}{ Injected drugs* } \\
\hline No & 1 & 1 \\
\hline Yes & 1.83 (1.21 to 2.77$)$ & $1.01(0.54$ to 1.90$)$ \\
\hline \multicolumn{3}{|c|}{ Shared cooker, cotton or water for injecting* } \\
\hline No & 1 & 1 \\
\hline Yes & 2.93 (1.68 to 5.14$)$ & $2.89(1.34$ to 6.24$)$ \\
\hline \multicolumn{3}{|l|}{ Main sexual partner's HIV status* } \\
\hline No main partner & 1 & 1 \\
\hline HIV - or unknown & 1.95 (1.15 to 3.30$)$ & $2.36(1.33$ to 4.21$)$ \\
\hline $\mathrm{HIV}+$ & $5.98(3.20$ to 11.17$)$ & 6.99 (3.47 to 14.06$)$ \\
\hline \multicolumn{3}{|l|}{ Occasional sexual partners* } \\
\hline No & 1 & 1 \\
\hline Yes & $1.50(0.98$ to 2.30$)$ & 1.44 (0.85 to 2.44$]$ \\
\hline
\end{tabular}

*During the six months prior to the visit; †odds ratio per year increase in date of visit; łpatients with possible depression (score $>17$ in the French version of CES-D administered at visit" ${ }^{12}$ ).

to $19.7 \%, p=0.0001$ ) as well as within each group of patients (from $44.1 \%$ to $14.7 \%$ among those who were prescribed HAART, $\mathrm{p}=0.002$, and from $49.4 \%$ to $20.8 \%$ among those who were not, $\mathrm{p}=0.0001)$. Self report of at least one episode of sharing injection equipment (syringe, cooker or cotton) also decreased over time (from $29.5 \%$ to $5.9 \%$ among those who were prescribed HAART, $\mathrm{p}=0.008$, and from $19.5 \%$ to $5.8 \%$ among those who were not, $\mathrm{p}=0.0001$ ). Among HAART treated patients $17.6 \%$ reported no sexual activity at follow up while the proportion was $13.6 \%$ among those not treated $(p=0.55)$. There was no significant change over time with respect to the numbers of main or occasional partners, or both. The frequency of patients reporting at least one episode of oral sex significantly decreased for both groups of patients (from $79.4 \%$ to $55.9 \%, p=0.021$ among HAART treated patients and from $83.1 \%$ to $57.8 \%, \mathrm{p}<10^{-3}$ among the others); concerning anal sex, the observed declines did not reach a conventional significance level (from $47.1 \%$ to $29.4 \%$ among HAART treated patients, $\mathrm{p}=0.109$ and from $31.2 \%$ to $24.0 \%, \mathrm{p}=0.054$ among the others patients). Frequency of HIV related risky sexual behaviour reported during the prior six months declined, but this decline reached statistical significance only in the group of patients who were prescribed HAART (from $47.1 \%$ to $23.5 \%$, $\mathrm{p}=0.008$ ), and not in the untreated group (from $43.5 \%$ to $35.7 \%, \mathrm{p}=0.10)$.

Table 2 shows the estimated odds ratios for the univariate and multivariate GEE models for HIV related sexual risk behaviour. After multivariate adjustment, female gender, dec- laration of risky injecting behaviours, alcohol consumption ( $\geq 5$ glasses per day), having a high score on the CES-D depression scale, ${ }^{11}{ }^{12}$ having a steady relationship with a sexual partner (with an increased risk for those belonging to a seroconcordant HIV positive couple) were factors associated with unprotected sexual intercourse in the previous six months. But table 2 also confirmed that prescription of HAART during follow up was associated with a reduced likelihood of sexual risk behaviour.

\section{DISCUSSION}

HAART, by lowering viral load, so people may feel better, raised concerns about a potential increase or resumption of HIV related risky behaviours. These previous concerns were based mainly on cross sectional surveys about beliefs and attitudes toward safe sex practices among HIV infected gay men. ${ }^{13-16}$ (Also two abstract proceedings F Hickson, et al, 12th World AIDS Conference, Geneva, 1998; RH Remien, et al, 12th World AIDS Conference.) Our data from an ongoing cohort of HIV infected IDUs do not support these pessimistic predictions that initiation of HAART, or the improvement in health observed with HAART initiation, may create a basis for initiation or resumption of risk behaviours. In fact, our data show the reverse, namely that those who were prescribed HAART during follow up were less likely to practise episodes of unsafe sex than those who remained naive of such antiretroviral treatments. 


\section{Key points}

- Concerns have been raised that recent improvements in HIV care because of diffusion of highly active antiretroviral therapies (HAART) may favour continuation or relapse to risk behaviours among HIV infected patients.

- Failure of secondary prevention among HAART treated patients may create a new threat for public health through transmission of HIV viral strains that have already acquired genetic resistance characteristics against actual treatments.

- Data from the French MANIF 2000 cohort of patients HIV infected through injecting drug use do not support these pessimistic predictions. Proportion of patients who reported episodes of unprotected sexual intercourse during follow up significantly decreased in the HAART treated group but not in the rest of the sample.

- The study points out the inadequacy of delaying or withholding access to HAART among HIV infected IDUs because of a priori fears that it may facilitate risk behaviours.

Of course, generalisation of our findings to other populations of HIV infected persons remains to be determined. Firstly, our study was not a randomised clinical trial but an observational cohort study in which physicians remained free to make a clinical decision about initiation of HAART and to select patients who had access to these treatments. It had already been shown that in routine clinical practice, physicians' perceptions of IDU patients' non-adherent behaviours may explain why these patients had less and delayed access to HIV infection antiretroviral therapies. ${ }^{17}{ }^{18}$ Because of the relatively low proportion of patients in our cohort who had access to HAART, and although extramedical characteristics at enrolment, including gender, age, and risky behaviours, were similar between those who were ultimately prescribed HAART and those who were not, we cannot totally exclude that some selection bias might have occurred. Prescribing physicians may have been more eager to recommend HAART in patients whose personal characteristics seemed to them as facilitating adherence to both treatment and recommendations for secondary prevention. Secondly, our assessment of behaviours was based on self reports, in which socially desirable responding cannot be excluded. Evidence supporting the accuracy of self reports about drug use and sexual practices by IDUs has however been provided by various studies, ${ }^{19} 20$ including our own MANIF 2000 cohort study. ${ }^{21}$ Finally, our period of observation after initiation of HAART remained confined to a short period. It is sometimes argued that a three month follow up is long enough for observing behaviour change to occur and stabilise. ${ }^{22}$ We cannot exclude that long term impact of HAART on sexual and social life of patients may create new opportunities for risk behaviours. Therefore long term follow up is therefore needed, including a more detailed assessment, on the extent to which HAART may be associated with an increase in frequency of episodes of sexual intercourse among treated patients. It remains to be confirmed by additional follow up that patients with continued successful treatment are not more likely than untreated patients to "relapse" to high risk behaviours.

In any case, about one third of our sample of HIV infected IDUs, who benefit from free medical care in French health care system, reported at least one episode of unprotected sexual intercourse during the six months before the last follow up visit. Factors that have previously been shown to be associated with sexual risky behaviours in other studies among people living with HIV/AIDS were also present in our cohort. Some of these factors, like depressive symptoms ${ }^{23}{ }^{24}$ or heavy alcohol consumption, ${ }^{25}{ }^{26}$ can be targeted for counselling and interventions aimed at facilitating secondary prevention. Of particular concern, in the context of HAART, is the confirmation, in our analysis as in many others, ${ }^{21}{ }^{27-29}$ that unprotected sexual intercourse was more likely when both partners were known to be HIV infected. Unsafe sex between HIV positive seroconcordant people has sometimes been interpreted in terms of "negotiated safety". ${ }^{30}$ With the advent of HAART, it has become an important issue to the extent that potential reinfections with viral strains that had already become resistant to antiretroviral drugs may jeopardise the effectiveness of the newly available therapeutic regimens.

The availability of HAART certainly calls more attention about the necessity to increase efforts for both primary and secondary prevention among patients who are already HIV infected. ${ }^{31}$ But, our study counters the a priori fears that HAART may facilitate risk behaviours among HIV infected IDUs. Continuing to delay or withhold access to HAART for all IDUs as a class of patients cannot be supported by these data.

Funding: The MANIF 2000 cohort study is supported by the French National Agency for AIDS Research (ANRS).

Conflicts of interest: none.

\section{Authors' affiliations}

A-D Bouhnik, Y Obadia, Regional Centre for Disease Control of South-Eastern France (ORS-PACA), Marseilles, France

A-D Bouhnik, J P Moatti, Y Obadia, INSERM Research Unit 379 Epidemiology and Social Sciences Applied to Medical Innovation, Institut Paoli-Calmettes, Marseilles, France

J P Moatti, Department of Economics, University of Aix-Marseilles II,

France

D Vlahov, Center for Urban Epidemiologic Studies, New York Academy of Medicine, USA

H Gallais, Department of Infectious Diseases, "La Conception" Hospital, Marseilles, France

P Dellamonica, Department of Tropical and Infectious Diseases,

"L'Archet" Hospital, Nice, France

The MANIF 2000 Study Group includes: , C Boirot, A D Bouhnik, M P Carrieri, J P Cassuto, P Dellamonica, N Escaffre, G Fuzibet, H Gallais, J A Gastaut, G Lepeu, A Loundou, C Marimoutou, D Mechali, J P Moatti, J Moreau, Y Obadia, C Pradier, D Rey, C Raynaud-Maurupt, A Schaeffer, A Sobel, B Spire, C Tamalet, F Trémolières, D Vlahov

\section{REFERENCES}

1 Deeks S, Smith M, Holodniy M, et al. HIV-1 protease inhibitors. A review for clinicians. JAMA 1997;277:145-53.

2 Kelly JA, Otto-Salaj LL, Sikkema KJ, et al. Implications of HIV treatment advances for behavioral research on AIDS: protease inhibitors and new challenges in HIV secondary prevention. Health Psychol 1998; 17:310-19.

3 Wainberg MA, Friedland G. Public health implications of antiretroviral therapy and HIV drug resistance. JAMA 1998:279:1977-83.

4 Hecht F, Grant R, Petropoulos C, et al. Sexual transmission of an HIV-1 variant resistant to multiple reverse-transcriptase and protease inhibitors. N Engl J Med 1998;339:307-1 1

5 Watkins KE, Metzger D, Woody G, et al. Determinants of condom use among intravenous drug users. AIDS 1993:7:719-23.

6 Centers for Disease Control and prevention. Continued sexual risk behavior among HIV-seropositive drug-using men. MMWR 1996;45:151

7 Catchpole MA, Mercey DE, Nicoll A, et al. Continuing transmission of sexually transmitted diseases among patients infected with HIV-1 attending genitourinary medicine clinics in England and Wales. BM 1996;312:539-42.

8 Rhodes T, Myers T, Bueno R, et al. Drug injecting and sexual safety cross-national comparisons among cocaine and opioid injectors. In Stimson G, Des Jarlais DC, Ball A, eds. Drug injecting and HIV infection. London: WHO/UCL Press, 1998:130-47.

9 Semaan S, Kotranski L, Collier K, et al. Temporal trends in HIV risk behaviors of out-of-treatment injection drug users and injection drug users who smoke crack. J Acquir Immune Defic Syndr Hum Retrovirol 1998; 19:274-81

10 Liang KY, Zeger SL. Longitudinal data analysis using generalized linear models. Biometrika 1986;73:13-22.

11 Radloff LS, The CES-D scale: a self-report depression scale for research in the general population. Applied Psychology Measurement 1977:3:385-401.

12 Fuhrer F, Rouillon F. La version française de l'échelle CES-D. Description et traduction de l'échelle d'autoévaluation. [In French]. Psychiatrie and Psychobiologie 1989;4:163-6.

13 Elford J, Bolding G, Maguire, M, et al. Combination therapies for HIV and sexual risk behavior among gay men. J Acquir Immune Defic Syndr 2000;23:266-71. 
14 Kelly JA, Hoffman RG, Rompa D, et al. Protease inhibitor combination therapies and perceptions of gay men regarding AIDS severity and the need to maintain safer sex. AIDS 1998;12:F91-5.

15 Kravcik S, Victor G, Houston S, et al. Effect of antiretroviral therapy and viral load on the perceived risk of HIV transmission and the need for safer sexual practices. J Acquir Immune Defic Syndr Hum Retrovirol 1998; 19:124-9.

16 Vanable PA, Ostrow DG, McKirman D, et al. Impact of combination therapies on HIV risk perceptions and sexual risk among HIV-positive and HIV-negative gay and bisexual men. Health Psychol 2000;19:134-45.

17 Strathdee SA, Palepu A, Cornelisse PG, et al. Barriers to use of free antiretroviral therapy in injection drug users. JAMA 1998;280:547-7.

18 Carrieri MP, Moatti JP, Vlahov D, et al. Access to antiretroviral treatment among French HIV infected injection drug users: the influence of continued drug use. J Epidemiol Community Health 1999:53:4-8.

19 Samuels JF, Vlahov D, Anthony JC, et al. Measurement of HIV risk behaviors among intravenous drug users. British Journal of Addiction 1992;87:417-8

20 Robles RR, Marrero CA, Matos TD, et al. Factors associated with changes in sex behavior among drug users in Puerto Rico. AIDS Care 1998;10:329-38.

21 Gollub EL, Rey D, Obadia Y, et al. Gender differences in risk behaviors among HIV+ persons with an IDU history. Sex Transm Dis 1998:25:483-8

22 Ickovics JR, Morrill AC, Beren SE, et al. Limited effects of HIV counseling and testing for women : a prospective study of behavioral and psychological consequences. JAMA 1994;272:443-8.
23 Kelly JA, Murphy DA, Bahr GR, et al. Factors associated with severity of depression and high-risk sexual behavior among persons diagnosed with human immunodeficiency virus (HIV) infection. Health Psychol

1993;12:215-19.

24 Robins AG, Dew MA, Kingsley LA, et al. Do homosexual and bisexual men who place others at potential risk for HIV have unique psychosocial profiles. AIDS Educ Prev 1997;9:239-51.

25 Kline A, van Landingham M. HIV-infected women and sexual risk reduction: the relevance of existing models of behavior change. AIDS Educ Prev 1994;6:390-402.

26 Perry MJ, Solomon L, Winett RA, et al. High risk sexual behavior and alcohol consumption among bar-going gay men. AIDS 1994;8:1321-4.

27 Van Ameijden EJ, Langendam MW, van den Hoek JAR, et al. Large declines in sexual risk behavior with non-commercial partners among heterosexual IDUs in Amsterdam, 1989-1995. Am J Epidemiol 1996;144:722-81.

28 Marks G, Ruiz MS, Richardson JL, et al. Anal intercourse and disclosure of HIV infection among seropositive gay and bisexual men. J Acquir Immune Defic Syndr Hum Retrovirol 1994;7:866-9.

29 Hankins C, Gendron S, Tran T, et al. Sexuality in Montreal women living with HIV. AIDS Care 1997;9:261-71.

30 Kippax S. A commentary on negotiated safety. Venereology 1996;9:96-7.

31 Ostrow DG Practical prevention issues, In: Ostrow DG, Kalichman SC eds. Psychosocial and public health impacts of new HIV therapies. New York: Kluwer Academic/Plenum, 1999:151-69. 